\title{
Holoprosensefali'nin Prenatal Tanısında Ultrasonografi ve Manyetik Rezonans Görüntülemenin Kullanılması
}

\author{
Use of Magnetic Resonance Imaging and Ultrasonography in Prenatal Diagnosis of Holo- \\ prosencephaly
}

Ayhan ATIGAN

Ar. Gör. Dr. Pamukkale Üniversitesi Tıp Fakültesi Kadın Hastalıkları ve Doğum Anabilim Dalı, DENIZLİ

Öz

Holoprosensefali (HPE), erken gestasyonel dönemde ön beynin tamamen veya yetersiz ayrılmasıla karakterli beynin yapisal bir anomalisidir. HPE'lerin yaklaşık \%80'nine, karakteristik kranyofasyal anomaliler eşlik eder. HPE, yaklaşık 16.000 canlı doğumda ve 250 embryoda bir ortaya çıkan, insanda sık görülen beyin defektidir. Sıklıkla, ilk kez gebelikteki ultrason sırasında tanımlanır. Hafif ve orta derecede beyin anomalisi olan infantlar ise yaşamın ilk yılının sonuna kadar tanı alamayabilirler. Çalışmamızın amacı kliniğimizde HPE tanısı alan olguya eşlik eden ek anomalileri incelemek ve bu bulguları literatür ile eşliğinde gözden geçirmektir. Oldukça küçük başa sahip olan fetüslerde sonografik inceleme çok zor olabilir ve HPE'ye ait bulgular kolaylıkla, ilk trimesterde gözden kaçabilir. HPE’ye ait bulguların saptanabilmesi için ilk trimesterde fetusa ait serebral yapıların çok dikkatli incelenmesi önemlidir.

Anahtar Kelimeler: Holoprosensefali (HPE), gebelik, görüntüleme

\section{Abstract}

Holoprosencephaly (HPE) is a morphological anomaly of the brain that is characterised with unsuccessful or incomplete separation of the forebrain in early gestation. Approximately $80 \%$ of HPE cases is accompanied by a spectrum of characteristic craniofacial anomalies. HPE is a common forebrain defect in humans, with a prevalence of 1:250 in embryos and 1:16,000 among live-born infants. HPE is usually diagnosed by gestational ultrasound examination. Infants with mild or moderate brain anomalies may not be diagnosed until the first year of life. The aim of the study was to search for the defects of HPE in our case and discuss the findings in view of the literature. The ultrasonographic examination of the brain in fetuses with a small head may be difficult and the first trimester features of HPE can be easily overlooked. It is important to examine cerebral structures of fetuses very carefully in the first trimester to detect the HPE features

Key Words: Holoprosencephaly (HPE), pregnancy, imaging

\section{GİRIŞ}

Holoprosensefali (HPE), embriyonel hayatın 35- 42 günleri arasında telensefalon ve diensefalona bölünmesi gereken prozensefalonun çeşitli derecelerde yetersiz bölünmesi sonucu oluşan beynin yapısal bir anomalisidir (1). HPE’lerin yaklaşık \% 80'ine, karakteristik kraniyofasyal anomaliler eşlik etmektedir. HPE, yaklaşık 16,000 canlı doğumda ve 250 embriyoda bir ortaya çıan bir beyin defektidir (1, 2). Tanıdan, sıklıkla gebelik ultrasonografi muayenesinde şüphelenilmektedir. Ancak manyetik rezonans görüntüleme (MRG) kesitlerinin HPE açısından bulguları daha belirleyici olabilmektedir (2). Hafif ve orta derecede beyin anomalisi olan yenidoğan bebekler ise yaşamın ilk yılının sonuna kadar tanı alamayabilirler. Bu nedenle poliklinik vizitlerine ultrasonografi ile muayene atlanmamalidir.

\section{OLGU SUNUMU}

Otuz dört yaşında, gravida 3, parite 1 (miadında, normal spontan vajinal doğum), yaşayan 1 , abortus 1 olan gebe son adet tarihine göre 22. haftada kontrol amaciyla başvurdu. Daha öncesinde takibi olmayan gebenin soy geçmişine ait özellik bulunmazken, hastadan ruh hali ve mental kapasitesi nedeniyle detaylı anamnez almak zordu. Gebeliğinde folik asit kullanmayan gebenin ailesinde tanı konulmuş genetik hastalık yoktu. Yapılan ultrasonografisinde lateral ventriküllerin tek boşluk oluşturduğu gözlendi.

$\begin{array}{ll}\text { İletişim: } & \begin{array}{l}\text { Dr. Ayhan Atıgan, Pamukkale Üniversitesi Tıp Fakültesi } \\ \text { Kadın Hastalıkları ve Doğum AD, DENIZLI }\end{array} \\ \text { DOI: } & \mathbf{1 0 . 1 7 5 1 7 / k s u t f d . 4 6 3 8 6 9}\end{array}$

Yapılan fetal MRG değerlendirmesinde (Resim 1a-b) lateral ventriküllerin tek boşluk halinde olduğu ve talamus füzyonu teyit edildi. Gebenin tıbbi terminasyonu kabul etmesi üzerine gebelik sonlandırılmasına gidildi. Terminasyon sonrası fetüsün makroskopik incelenmesinde alobar holoprosensefali, burun kökü basık, sağ göz anoftalmi, sol göz ekzoftalmi, hipotelorizmi içeren atipik yüz görünümü yanında kraniyal yapıda deformasyon da mevcuttu (Resim 2).

\section{TARTIŞMA}

HPE 1:16000 oranında görülen erkek/kız oranı 1/1 olan konjenital bir santral sinir sistemi anomalisidir (2). Bu yapisal anomali, genellikle sporadik olup etyolojide maternal diyabetik, radyasyona maruz kalma, salisilat ve alkol kullanımı, Rubella, Sitomegalovirüs (CMV) ve Toksoplazma enfeksiyonları rol oynayabilir.

HPE şiddeti frontal lobun gelişme miktarı ile orantılıdır. Yüz anomalileri tek göz (siklopi), tek burun deliğinden hipotelorizme kadar değişen bir yelpaze gösterirken genellikle mikrosefali tabloya eşlik etmektedir. Olguların birçoğunda septum pellusidum yoktur (2). HPE, en sık trizomi 13 olmak üzere kromozom anomalileri ile de birlikte olabilmektedir.

En ağır patolojiden en hafife doğru alobar, semilobar ve lobar olmak üzere 3 şekilde ortaya çıkmaktadır. Semilobar

\begin{tabular}{|c|c|}
\hline Tel & : 05447282378 \\
\hline E-Posta & : dratigan@hotmail.com \\
\hline Geliş Tarihi & : 25.09 .2018 \\
\hline Kabul Tarihi & : 31.12 .2018 \\
\hline
\end{tabular}


Resim 1 a-b. Manyetik rezonans görüntüleme bulguları: Frontal kesitlerde tek ventrikül oluşumu ve interhemisferik sulkusun yokluğu dikkat çekiyor.
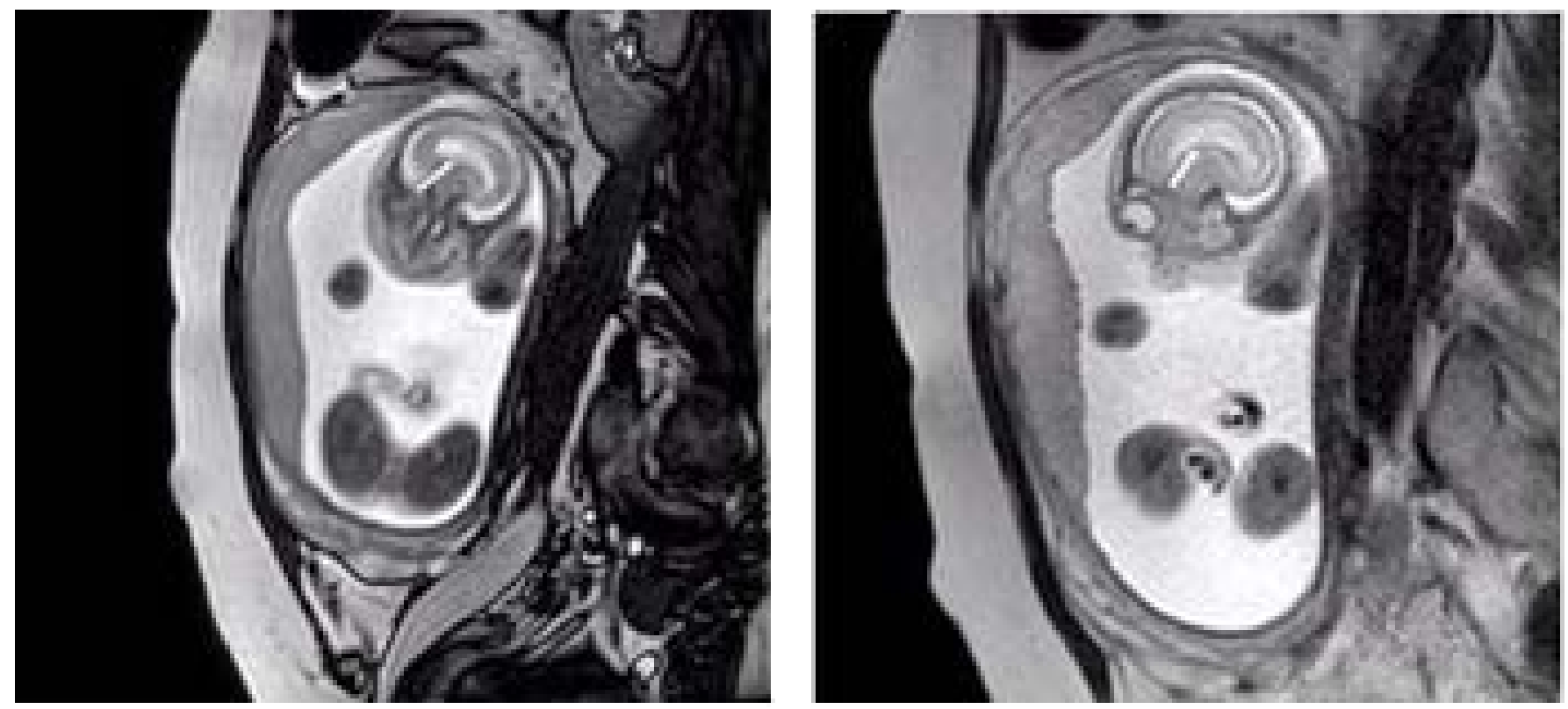

Resim 2a-b: Fetüsün terminasyon sonrası makroskopik görünümü. Terminasyon sonrası fetüsün incelenmesinde alobar holoprosensefali, burun kökü basıklğ̆l, sağg göz anoftalmi, sol göz ekzoftalmi, hipotelorizm görünümü.

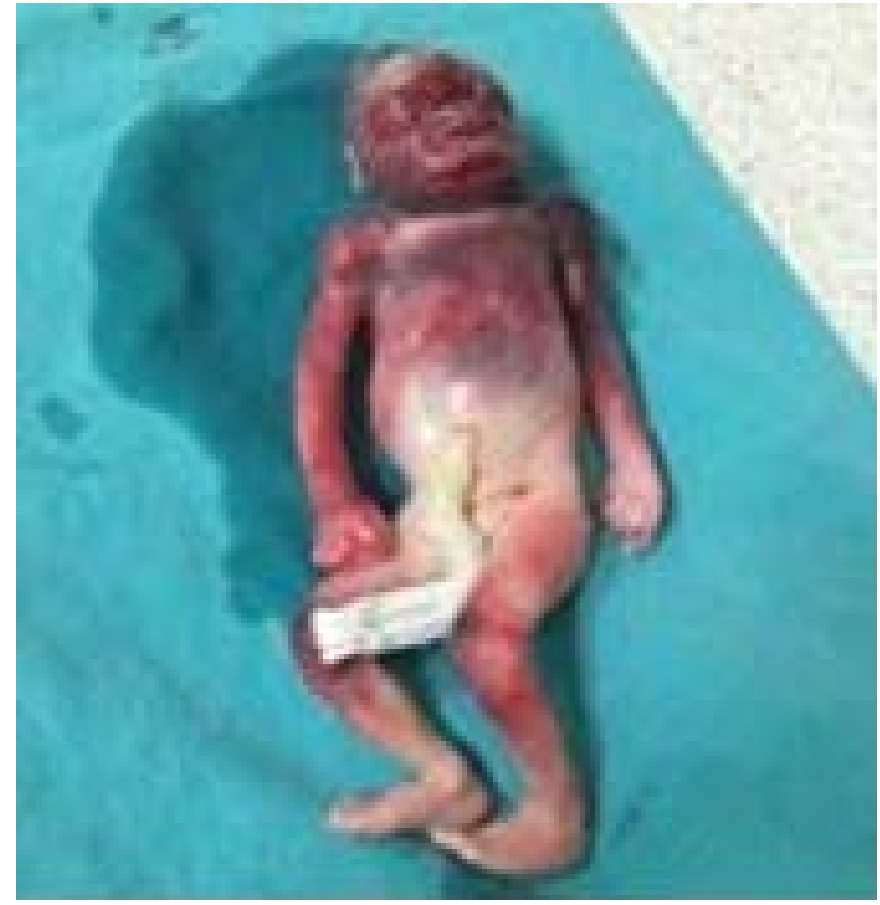

HPE, alobar'a göre daha seyrek görülmekte ve prognoz tipe göre değişmektedir $(3,4)$. Alobar HPE'li yenidoğanlar birkaç hafta içinde kaybedilirken semilobar tipinde yaşam şansı mevcuttur. Ancak bunlarda, mental retardasyon olaya eşlik edebilmektedir.

HPE tanısında koroid pleksuslara ait kelebek görüntüsünün izlenmemesi ve tek ventrikül görülmesi en değerli ipuçlarıdır $(1,2)$. MRG iyonizan radyasyon içermemesi, hastanın pozisyonunu değiştirmeden istenen her planda görüntü alabilmesi ve mükemmel yumuşak doku çözümleme gücü nedeniyle merkezi sinir sistemi incelemesinde primer görüntüleme yöntemi haline gelmiştir (3). MRG kesitlerindeki karakteristik görüntülerle klinik tablo arasında sıkı bir korelasyon mevcuttur (3).

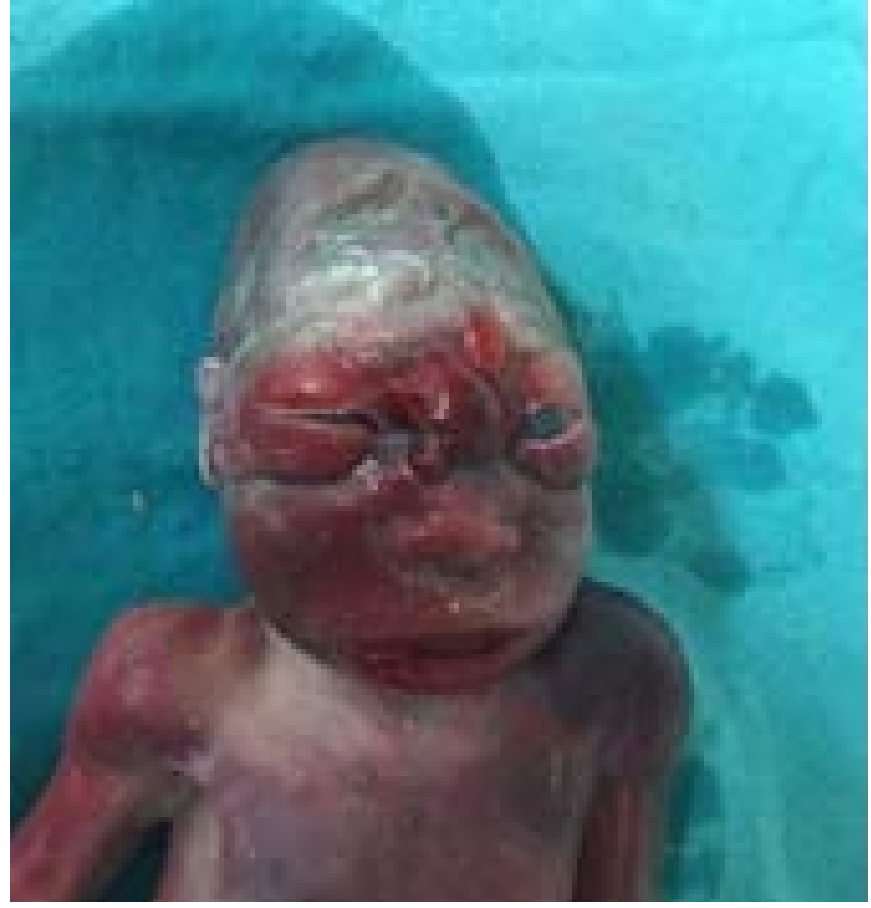

HPE oldukça nadir görülen bir santral sinir sistemi anomalisi olup, MRG ile prognoz ve genetik danışmanlık açısından daha detaylı bilgi edinmek mümkündür. Çalışmamız ile kliniğimizde 22. haftada tıbbi terminasyon uygulanan bir lobar holoprozensefali olgusunu sunarak, HPE'de karşılaştığımız radyolojik bulguları ve eşlik eden ek anomalileri güncel literatür eşliğinde tartıştık.

Çıkar İlişkisi: Yazar çıkar ilişkisi olmadığını beyan eder.

\section{KAYNAKLAR}

1. Tosun M, Torumtay AB, Malatyalıŏglı E, Çetinkaya M, Alper T, Kökçü A. Semilobar holoprozensefali: olgu sunumu. OMÜ Tip Derg 2006; 23: 138-40. 
2. Griffiths PD, Jarvis D. In utero MR imaging of fetal holoprosencephaly: a structured approach to diagnosis and classification. AJNR Am J Neuroradiol 2016; 37: 536-43.

3. Peruzzi P, Corbitt RJ, Raffel C. Magnetic resonance imaging versus ultrasonography for the in utero evaluation of central nervous system anomalies. J Neurosurg Pediatr 2010; 6: 340-5.
4. Özsunar Y, Köseoğlu K. Semilobar holoprozensefalide manyetik rezonans bulguları: Olgu sunumu. İnönü Üniv Tip Fak Derg 2002; 9: 127-30. 